\title{
Orientação para o mercado de empresas de base tecnológica produtoras de software: uma análise à luz do modelo de George Day
}

\author{
Agnelo Câmara de Mesquita Júnior \\ Fernando Gomes de Paiva Júnior***
}

\begin{abstract}
Resumo
O presente trabalho analisa os elementos e processos que integram a orientação para o mercado (OPM) no segmento de tecnologia da informação e comunicação em empresas de base tecnológica da cidade do Recife, Pernambuco. Para tanto, são descritos os conceitos de empresa de base tecnológica e de processo de OPM, com atenção especial ao modelo proposto por George Day. Foi conduzido um estudo de caso cuja população é composta por duas empresas pernambucanas que desenvolvem softwares como principal atividade. $\mathrm{O}$ instrumento de coleta utilizado foi uma entrevista elaborada com base em um questionário concebido por Day, capaz de estabelecer características típicas das organizações orientadas para o mercado e fornecer subsídios necessários à implementação de aperfeiçoamentos por gestores e colaboradores.
\end{abstract}

Palavras-chave: Marketing. Orientação ao mercado. Tecnologia da informação.

* Especialista com MBA em Gestão Estratégica de Marketing. Universidade Federal de Pernambuco, Recife, Pernambuco, Brasil. E-mail: agnelocamara@hotmail.com

** Doutor em Administração pela UFMG e professor Associado II da Universidade Federal de Pernambuco. 


\section{Introdução}

Diante da alta competitividade experimentada pelos mercados, tornou-se imperativo para as organizações investir em métodos e processos que garantam tanto a diferenciação dos produtos e serviços oferecidos como a criação de valor para os stakeholders envolvidos na negociação dessas mercadorias. Particularmente, no mercado de tecnologia da informação e comunicação (TIC), determinar a criação de valor por meio do desenvolvimento de produtos inovadores, elaborados de acordo com as necessidades e expectativas dos clientes ganha contornos particulares. Mohr et al. (2011) argumentam que as empresas de alta tecnologia, com pesadas estruturas burocráticas, precisam lutar para se manter inovadoras e propiciar essa característica aos seus produtos. No caso de organizações do mesmo setor, mas de porte menor, o desafio reside em mudar sua postura unicamente voltada para a tecnologia e engenharia para outra orientada para o mercado (OPM).

Embora seja comum enxergar a orientação ao mercado como fator intrínseco à sobrevivência e/ou diferenciação de uma empresa em relação aos seus concorrentes, poucas organizações, na verdade, o fazem com maestria. No caso das empresas de tecnologia da informação, tal prática constitui-se uma das tarefas mais desafiadoras, pois algumas barreiras impeditivas surgem, transformando a OPM em verdadeira odisseia. Day (2001) lembra a ausência de uma cultura que, de fato, envolva toda a organização da necessidade de estar orientada ao mercado e a confusão sobre o que de fato significa o termo OPM como alguns dos percalços experimentados por essas organizações.

Mohr et al. (2011), citam a filosofia do desenvolvimento de produtos buscando tão somente o estado da arte da tecnologia e a ausência de colaboração entre os setores de pesquisa e desenvolvimento (P\&D) e Marketing como elementos dificultadores à orientação ao mercado.

Sendo a orientação para o mercado uma prática multifacetada, constituindo campo complexo de definições, este estudo deteve-se a identificar e analisar elementos constitutivos da OPM com base no modelo de análise proposto por Day (2001). Para tanto, foram conduzidas duas entrevistas apoiadas em questionário previamente estruturado com o intuito de estabelecer um comparativo de cenários, sendo um favorável à OPM e outro com elementos impeditivos dessa prática.

Diante das considerações, o estudo aborda, em um primeiro momento, definições sobre o que é uma empresa de base tecnológica. Em seguida, são elaboradas reflexões sobre as concepções de orientação para o mercado, discorrendo-se sobre as estruturas apresentadas por alguns pesquisadores, relacionando-as com as atividades das empresas de tecnologia da informação. A seguir, a pesquisa dedicará 
análise mais profunda ao modelo de OPM apresentado por George Day, pormenorizando cada um daqueles que autor chama de elementos-chave de empresas orientadas para o mercado que lograram êxito em suas atividades. Em seguida, este levantamento ilustrará tais observações por meio das entrevistas com os dirigentes de duas empresas de base tecnológica, que apresentam posições e condições distintas no que tange à OPM.

\section{Referencial teórico}

O referencial teórico do presente trabalho abordará definições referentes a temas-chave da discussão aqui proposta. Em primeiro lugar, apresentam-se considerações sobre o conceito de empresa de base tecnológica, evidenciando suas atividades e sua composição organizacional. Em seguida, o estudo discutirá aspectos relacionados à orientação para o mercado, com especial atenção para o modelo proposto por George Day (2001). Os elementos constitutivos da análise do autor serão pormenorizados e cruzados com observações de outros autores, a fim de que se tenha, ao final, um campo de discussões capaz de fundamentar uma análise sólida dos cenários abordados neste levantamento.

\subsection{Empresa de base tecnológica}

Dada a importância dos desenvolvimentos tecnológicos na economia e ao caráter plural assumido pelo termo tecnologia, categorizar determinados setores como de alta ou baixa tecnologia e empresas como de base tecnológica pode não ser tarefa tão fácil. Entretanto, percebe-se que vários estudos analisam o escopo de atividades dessas organizações com base na sua relação com tecnologia, na qualificação dos colaboradores e na influência da tecnologia na sua atuação de mercado. Marcovitch, Santos e Dutra (1986), por exemplo, entendem que as empresas de base tecnológica já são orientadas, desde o seu nascimento, a desenvolver ou oferecer serviços que envolvem elevado conteúdo tecnológico. Essa mesma visão pode ser corroborada com os trabalhos de Capon e Glazer (1987), que definem tais organizações com a expressão empresas de alta tecnologia, que, por conceituação, são aquelas envolvidas no projeto, desenvolvimento e introdução de novos produtos e/ ou processos inovadores de fabricação por meio da aplicação sistemática de conhecimento técnico e científico.

Frequentemente associa-se o conceito de empresa de base tecnológica a processos de inovação, vinculando a competitividade dessas organizações à sua 
capacidade de desenvolvimento de produtos e serviços, seja por meio de novidades incrementais ou radicais. É o caso de estudos como o de Piscopo (2010), que entende empresas de base tecnológica como sinônimo de alta tecnologia, caracterizando-as com empresas atuantes no setor, cuja competitividade fundamenta-se na sua capacidade de inovação em negócios como software, semicondutores, química fina, biotecnologia, aeronáutica, tecnologia da informação e comunicação.

As indústrias de alta tecnologia possuem características em comum que abrangem um grupo de incertezas: a) de mercado, englobando aspectos como as necessidades do consumidor e os impactos das novas tecnologias no futuro; b) tecnológicas, que envolvem o funcionamento do produto, cronograma de entrega de funcionalidades e de suporte ao cliente; c) volatilidade competitiva (Mohr et al., 2011). Portanto, esse grupo de incertezas descreve quais são as empresas que concorrem nesse mercado, quais os produtos oferecidos e quais ferramentas e técnicas são utilizadas por essas organizações.

Como define o Glossário da Financiadora de Estudos e Projetos, empresa de base tecnológica é aquela "de qualquer porte ou setor que tenha na inovação tecnológica os fundamentos de sua estratégia competitiva". ${ }^{1}$ De acordo com o que informa a empresa pública, para que uma organização atenda a essa condição é necessário apresentar pelo menos duas das características, conforme apresentadas Quadro 1.

Quadro 1 - Características das empresas de base tecnológica

\begin{tabular}{|l|l|}
\hline \multicolumn{1}{|c|}{ Critério } & \multicolumn{1}{c|}{ Descrição } \\
\hline Produtos & $\begin{array}{l}\text { Desenvolver produtos, serviços ou processos produtivos ou processos tecnologicamente no- } \\
\text { vos ou melhorias tecnológicas significativas em produtos ou processos existentes. }\end{array}$ \\
\hline Faturamento & $\begin{array}{l}\text { Obter pelo menos } 30 \% \text { de seu faturamento [...] pela comercialização de produtos protegidos } \\
\text { por patentes ou direitos de autor ou em processo de obtenção das referidas proteções. }\end{array}$ \\
\hline Investimento & $\begin{array}{l}\text { Encontrar-se em fase pré-operacional e destinar pelo menos o equivalente a } 30 \% \text { de suas } \\
\text { despesas operacionais [...] a atividades de pesquisa e desenvolvimento tecnológico. }\end{array}$ \\
\hline Porte & $\begin{array}{l}\text { Não se enquadrar como micro ou pequena empresa e destinar pelo menos 5\% de seu fatura- } \\
\text { mento a atividades de pesquisa e desenvolvimento tecnológico. }\end{array}$ \\
\hline $\begin{array}{l}\text { Parceria com } \\
\text { instituições } \\
\text { de ensino }\end{array}$ & $\begin{array}{l}\text { Não se enquadrar como micro ou pequena empresa e destinar pelo menos 1,5\% de seu fa- } \\
\text { turamento a instituições de pesquisa ou universidade para o desenvolvimento de projetos de } \\
\text { pesquisa que visem ao desenvolvimento de projetos de pesquisa relacionados ao desenvolvi- } \\
\text { mento ou aperfeiçoamento de seus produtos ou processos. }\end{array}$ \\
\hline $\begin{array}{l}\text { Recursos } \\
\text { humanos }\end{array}$ & $\begin{array}{l}\text { Empregar, em atividades de desenvolvimento de software, engenharia, pesquisa e desenvol- } \\
\text { vimento tecnológico, profissionais técnicos de nível superior em percentual igual ou superior a } \\
\text { 20\% do quadro de pessoal; }\end{array}$ \\
\hline $\begin{array}{l}\text { Grau de } \\
\text { instrução da } \\
\text { equipe }\end{array}$ & $\begin{array}{l}\text { Empregar, em atividades de pesquisa e desenvolvimento tecnológico, mestres, doutores ou pro- } \\
\text { fissionais de titulação equivalente em percentual igualou superior a 5\% do quadro de pessoal. }\end{array}$ \\
\hline
\end{tabular}

Fonte: disponível em: <http://www.finep.gov.br/biblioteca/glossario>. Acesso em: 27 dez. 2016. 
Para fins metodológicos, está sendo considerada a parcela das empresas de base tecnológica do segmento de tecnologia da informação desenvolvedoras de software ou hardware que atuam na produção de bens e serviços relacionados a esse mercado.

\subsection{Orientação para o mercado}

A OPM é uma das principais aptidões a serem desenvolvidas por empresas que desejam adquirir vantagens de longo prazo sobre os concorrentes e construir elementos organizacionais que possibilitem o direcionamento do foco permanente nessa direção. Sbragia e Lima (2013) defendem que a OPM apresenta-se como opção para as empresas que desejam se voltar para as necessidades do mercado e transformá-las em insumo para o aumento da capacidade competitiva das organizações.

Mas o que seria, de fato, orientação para o mercado? Alguns dos primeiros estudos da temática, como os de Kohli e Jaworski (1990) e Narver e Slater (1990) dão conta de que a OPM é um processo relacionado à geração e disseminação de inteligência de mercado objetivando a criação de valor superior para o cliente. A prática dessa filosofia implica, para os autores, a adoção de três focos: orientação para o cliente, para os competidores e coordenação interfuncional. Oliveira (2006) percebe o primeiro elemento como o processo de pesquisa e disseminação por toda a empresa de informações sobre os clientes, levando-a a conhecer a cadeia de valor de modo a construir um valor superior a eles. O segundo foco diz respeito à prática semelhante, só que voltada para os concorrentes. Conforme Pereira:

As empresas que quiserem ser efetivamente orientadas para o mercado deverão compreender como as necessidades dos clientes e as competências da organização interagem em um ambiente competitivo, pois todos esses fatores convergem na formação do valor percebido pelo cliente. Também é crucial que a organização conheça as ofertas e as competências de seus concorrentes, e a visão dos consumidores em relação a esses fatores (2005, p. 7).

A relação existente entre a OPM e o marketing relacional implica na compreensão do último como peça análoga à execução do primeiro. É o que ilustram estudos como o de Curi (2007), que traz como característica extrínseca à OPM uma cultura mais orientada para o cliente, a fim de oferecer-lhes produtos de maior valor agregado. É necessário ainda, segundo a autora, que a empresa estreite seus relacionamentos com o cliente, aumentando seu grau de fidelização para conseguir, 
assim, a vantagem competitiva de compreender melhor seus desejos e necessidades atuais e potenciais.

A OPM é definida por Abbade, Zanini e Souza (2012) como a cultura organizacional que desenvolve os comportamentos necessários à criação de valor elevado para o cliente, de forma mais eficaz e eficiente, gerando vantagem competitiva para a empresa. Os autores afirmam ainda que uma empresa orientada para 0 mercado oferece soluções que podem ir além das expectativas de valor dos seus clientes por meio da criação de um relacionamento em longo prazo. Esse esforço torna-se responsabilidade não só da área de marketing, mas de todos os setores da empresa, tornando-se elemento da cultura organizacional.

É possível elencar também outros elementos fundamentais para que as empresas consigam atingir um grau avançado de orientação para o mercado. A disseminação e utilização de inteligência de mercado são, segundo Mohr et al. (2011), suportes para a tomada de decisão da alta gerência, deixando este setor da organização mais comprometido com a criação de valor para o cliente. Para o êxito dessa filosofia, pressupõe-se uma gestão eficaz do conhecimento advindo de várias áreas da empresa, não apenas do marketing, bem como uma estrutura organizacional flexível, com responsabilidades compartilhadas e amplos processos de comunicação lateral.

Day (2001), por sua vez, apresenta um modelo próprio para compreender os elementos constitutivos de uma empresa orientada ao mercado. Segundo o pesquisador, essas organizações apresentam uma capacidade mais elevada para compreender, atrair e manter clientes importantes por criarem um contexto virtuoso que as possibilita atingir grau elevado de OPM. É sobre esse modelo que a pesquisa debruçar-se-á.

\subsubsection{Orientação para o mercado segundo Day}

A definição proposta por Day sintetiza um esquema (Figura 1) que relaciona alguns elementos-chave que, na visão do autor, compõem uma organização orientada ao mercado: 
Figura 1 - Elementos de uma orientação para o mercado

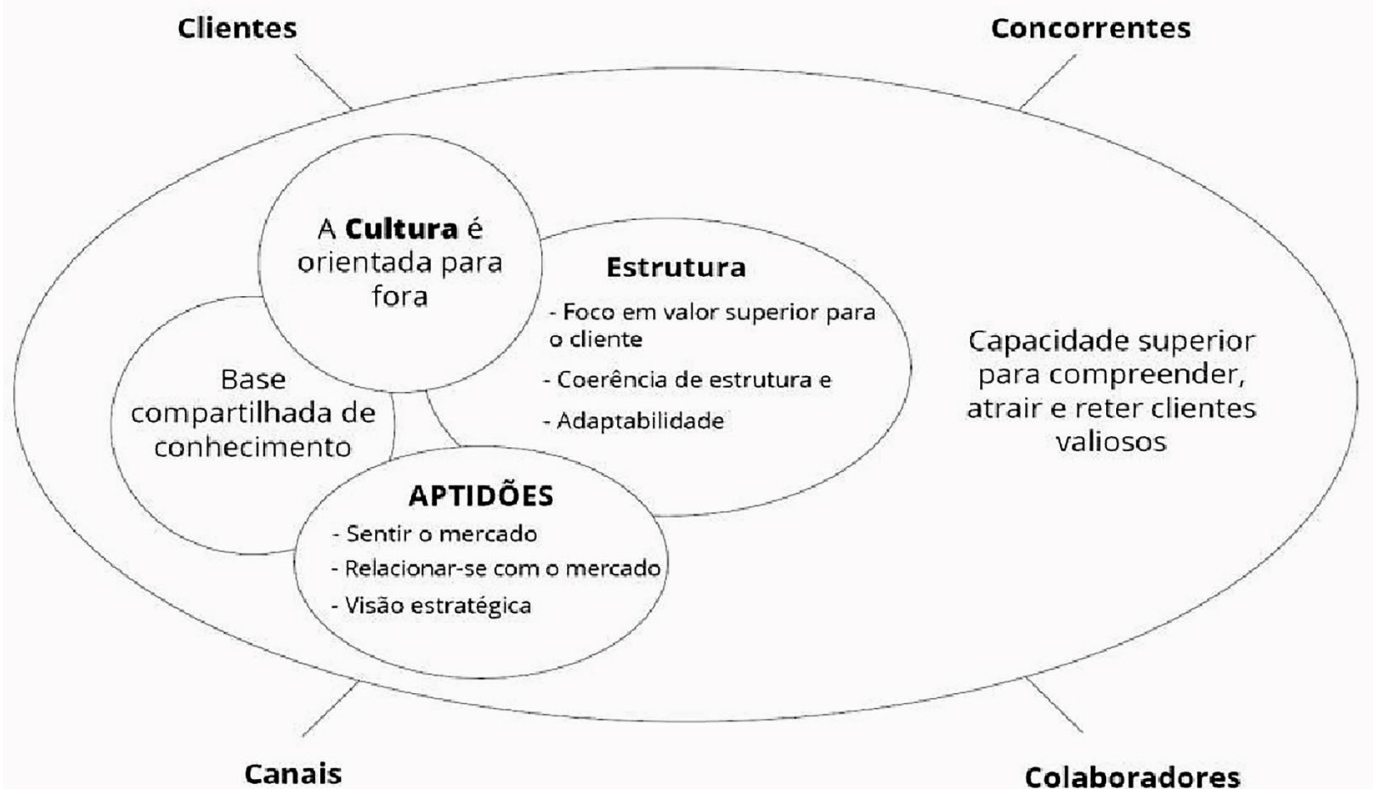

Fonte: Day (2001, p. 20).

A cultura orientada para fora deve impregnar toda a organização e enfatizar tanto um valor superior para o cliente como a busca contínua de novas fontes de vantagem. As aptidões, por sua vez, permitem que a empresa tenha uma visão estratégica avançada, estabelecendo conexões mais fortes e duradouras com seus clientes. As atividades da empresa passam a acompanhar a evolução do mercado, antecipando riscos e identificando novas oportunidades para o sucesso. Por fim, a estrutura organizacional dá subsídios para que a entrega de valor ao cliente seja adotada integralmente por todos os departamentos da empresa, de modo a criar unidade no seu dever-ser. $\mathrm{O}$ alicerce para esse contexto produtivo reside na base compartilhada de conhecimento, capaz de intensificar o comprometimento dos funcionários e construir relacionamentos mais duradouros com os clientes. Day defende cada um desses elementos precisa ser, no mínimo, tão bom quanto o melhor dos concorrentes para que a estratégica de atuação no mercado adotada seja proveitosa. 


\subsubsection{Cultura}

A cultura é uma dimensão organizacional complexa. Sua compreensão, enquanto elemento capaz de conferir à empresa condições para orientar-se para o mercado, requer olhares atentos a respeito do que vem a ser, de fato, uma cultura organizacional.

A cultura organizacional, pela ótica de Mohr et al., pode ser entendida como o conjunto de valores e crenças que permeia a empresa e que molda as normas (tácitas e explícitas) do seu comportamento. O conceito difere de clima organizacional, apresentado, segundo os autores, "como aquilo que realmente acontece na empresa, sendo um conjunto de comportamentos esperados, apoiados e recompensados" (2011, p. 60).

A essência da cultura de uma organização pode ser entendida, ainda, como reflexo da maneira como os negócios são conduzidos, do relacionamento com clientes e funcionários, do grau de autonomia ou liberdade que existe em suas unidades ou escritórios e o grau de lealdade expresso por seus funcionários com relação à empresa, que, desse modo, torna-se representante da mentalidade da empresa (RACHEL; SALOMÃO, 2011).

Frequentemente, a cultura organizacional é entendida como um dos fatores que contribuem para a competitividade das empresas, tendo especial relacionamento com a sua capacidade de inovação. $O$ entendimento dessa relação não é tarefa simples, pois envolve a necessidade de compreensão da empresa em seu aspecto macro, incluindo sua estrutura hierárquica, as funções desempenhadas por cada colaborador e os impactos delas na execução da missão da instituição. Para Maia et al.:

Priorizar formas de gestão que compreendam a execução especializada das diversas funções na operação de uma organização e sua integração adequada na cultura organizacional passa pelo alinhamento de planejamento, estratégia e compreensão do que efetivamente é o processo de inovação $(2014$, p. 7$)$.

George Day entende que a cultura orientada para o mercado deve ir além de uma alegoria dos discursos motivacionais, devendo permear todo o tecido organizacional. À empresa cabe promover incentivos, instrumentos e o contexto capaz de permitir o desenvolvimento de produtos capazes de fazer com que o cliente perceba valor superior neles. Dessa maneira, é possível entender que:

[...] "qualidade" passa a ser um esforço coletivo ao invés de uma máquina imposta, "fidelização de clientes" é uma motivação com significado e não uma frase mecânica e "equipes transfuncionais" são mecanismos de aperfeiçoamento ao invés de uma perda de tempo (2001, p. 22). 


\subsubsection{Aptidões}

As aptidões propostas por Day (2001) sugerem que uma organização orientada para o mercado deve ser capaz de desenvolver três habilidades necessárias para alcançar essa condição.

\section{Capacidade de sentir o mercado}

A primeira delas diz respeito à capacidade de sentir o mercado, identificando oportunidades de negócio e compreendendo mudanças. Essas organizações "[...] estão melhor equipadas para prever como os mercados irão reagir a ações concebidas para atrair ou manter clientes, melhorar relações com os distribuidores ou barrar concorrentes" (DAY, 2001, p. 68).

\section{Marketing de relacionamento}

A segunda habilidade refere-se ao marketing de relacionamento. Ao elencar esse ponto como primordial, quando se trata das aptidões de uma empresa OPM, Day (2001) afirma que é por meio dele que é possível adicionar valor ao cliente. A ampliação de serviços, incentivos e interações sob medida, para o autor, cria um ciclo virtuoso de compartilhamento de experiências de sucesso e benefícios mútuos, capaz de reforçar as conexões com os clientes a fim de se evitar que não migrem para a concorrência.

No ambiente de negócios de alta tecnologia, a necessidade de apresentar soluções cada vez mais complexas a um mercado cada vez mais exigente implica o estabelecimento de parcerias, alianças e relacionamento com o cliente. Com os curtos ciclos de vida e os custos elevados desse processo, é vital para as empresas de tecnologia da informação e comunicação considerarem o desenvolvimento conjunto de produtos como uma estratégia a ser explorada, seja em parceria com outros players do mercado ou mesmo com o consumidor final. Além disso, como essas organizações dependem dos consumidores tanto para a realização dos testes dos seus artefatos como para criar ideias para inovações, o estabelecimento de reações próximas aos clientes torna-se fonte preciosa de informações de mercado e de receita em longo prazo (Mohr et al., 2011, p. 91).

O nível de sintonia entre a empresa e o cliente tende a aumentar à medida que o marketing de relacionamento é trabalhado de forma eficaz. Dessa maneira, o consumidor percebe que é muito mais estratégico estar em contato com a empresa do que migrar para a concorrência. E esse comportamento será motivado não apenas pelo laço emocional, mas, sobretudo, pela conveniência, que pode ser ilustrada nas palavras de Monçores: 
Uma empresa orientada para as relações com seus clientes realiza o desenvolvimento de um "Relacionamento de Aprendizado Contínuo", que vai se tornando cada vez mais inteligente a cada interação, definindo com detalhamento cada vez maior as necessidades e os gostos individuais de um cliente específico. A lealdade do cliente não é gerada por um vínculo emocional ou senso de obrigação e dever, mas meramente por conveniência. Não há necessariamente exclusão dos laços emocionais como fatores significativos na manutenção de relacionamento com clientes. Mas estes laços não são o principal mecanismo em ação na garantia de lealdade do cliente. A conveniência, sim (2004, p. 12).

\subsubsection{Estrutura}

Day (2001) entende que a estrutura é o relacionamento estreito entre cultura, aptidões e processos da empresa, incluindo a habilidade em sentir o mercado, relacionar-se com ele e desenvolver a visão estratégica. $O$ pesquisador enumera então três características que distinguem as estruturas das empresas orientadas ao mercado daquelas que não o são, conforme se observa no Quadro 2:

Quadro 2 - Características inerentes à estrutura de empresas orientadas ao mercado

\begin{tabular}{|l|l|}
\hline \multicolumn{1}{|c|}{ Característica } & \multicolumn{1}{c|}{ Descrição } \\
\hline Foco estratégico no mercado & $\begin{array}{l}\text { Diz respeito à estrutura montada para oferecer valor mais ele- } \\
\text { vado ao cliente. As atividades e os investimentos funcionais } \\
\text { da empresa fazem parte de um modelo de operações centra- } \\
\text { das no mercado. }\end{array}$ \\
\hline Coerência de fatores & $\begin{array}{l}\text { Ocorre quando há sinergia entre a cultura, as aptidões e as } \\
\text { estruturas. Quando a coerência inexiste, ocorrem rupturas na } \\
\text { estratégia e implantação, criando lapsos que costumeiramen- } \\
\text { te são percebidos primeiramente pelo cliente. }\end{array}$ \\
\hline Flexibilidade & $\begin{array}{l}\text { Permite combinar a profundidade do conhecimento encontra- } \\
\text { do em uma hierarquia vertical com a sensibilidade das equi- } \\
\text { pes operacionais horizontais. }\end{array}$ \\
\hline
\end{tabular}

Fonte: elaborado pelo autor.

Além das características destacadas no Quadro 2, Day (2001, p. 67) afirma que as organizações orientadas para o mercado criam estruturas que desenvolvem suas aptidões para melhor sentir o mercado e com ele se relacionar. Esse arranjo, em seu estado de arte, inclui o modelo de organização, as outras aptidões da empresa e os sistemas de informações de apoio e recompensa. 


\section{Metodologia}

\subsection{Setor de tecnologia da informação no Brasil, alguns indicadores}

Dados da Associação Brasileira das Empresas de Software (2014) indicam que o crescimento dos investimentos em tecnologia da informação no Brasil foi expressivo, com um aumento de $15,4 \%$. O país figurou entre os dez maiores crescimentos setoriais no mundo e está na sétima posição em investimentos em TIC. O mercado doméstico de tecnologia da informação, que inclui hardware, software e serviços, movimentou 61,6 bilhões de dólares em 2013, representando 2,74\% do PIB brasileiro e $3 \%$ do total de investimentos no setor no mundo. Desse valor, 10,7 bilhões de dólares vieram do mercado de software e 14,4 bilhões de dólares do mercado de serviços, sendo que a soma desses dois segmentos já superou $40 \%$ do mercado total de tecnologia da informação.

O mercado interno de tecnologia, ainda segundo dados da associação, apresenta-se conforme o Quadro 3:

Quadro 3 - Mercado brasileiro de tecnologia da informação em 2013

\begin{tabular}{|c|c|c|c|c|}
\hline \multicolumn{5}{|c|}{ Mercado interno total de tecnologia da informação em 2013 (U\$ bilhões) } \\
\hline \multicolumn{2}{|l|}{ Hardware: 36,5} & Software: 10,7 & \multicolumn{2}{|c|}{ Serviços: 14,4} \\
\hline \multicolumn{5}{|c|}{ Distribuição regional do mercado brasileiro de tecnologia da informação ( 61,6 bilhões de dólares) } \\
\hline Região & Hardware & Software & Serviços & Total \\
\hline Norte & $2,14 \%$ & $2,23 \%$ & $2,17 \%$ & $2,17 \%$ \\
\hline Nordeste & $8,12 \%$ & $8,68 \%$ & $8,54 \%$ & $8,84 \%$ \\
\hline Centro-oeste & $13,93 \%$ & $11,03 \%$ & $13,73 \%$ & $13,21 \%$ \\
\hline Sudeste & $64,23 \%$ & $64,63 \%$ & $63,16 \%$ & $63,91 \%$ \\
\hline Sul & $11,58 \%$ & $13,43 \%$ & $12,41 \%$ & $12,31 \%$ \\
\hline Brasil & $100 \%$ & $100 \%$ & $100 \%$ & $100 \%$ \\
\hline
\end{tabular}

Fonte: Associação Brasileira das Empresas de Software (2014).

Já a Associação das Empresas de Serviços de Processamento de Dados (Assespro Nacional), em 2014, realizou censo em 434 empresas do setor de TIC no Brasil, averiguando sobre seus principais mercados: $37,8 \%$ das organizações pesquisadas 
responderam que concentram suas atividades em desenvolvimento de sistemas sob encomendas dos clientes; $22,4 \%$ ocupam-se com o setor industrial, desenvolvendo produtos de software aplicativo, e 17,7\% em serviços de suporte técnico.

\subsection{Descrição das empresas estudadas}

As empresas participantes do presente estudo, conforme apresentado anteriormente, são duas organizações do setor de tecnologia da informação e comunicação, desenvolvedoras de sistemas de informação e prestadoras de serviço de suporte e consultoria aos seus respectivos clientes. A fim de manter o sigilo solicitado pelos responsáveis pelas corporações, por motivos legais, o estudo nomeou as organizações como Alfa e Beta.

\section{Empresa Alfa}

Sediada na cidade do Recife, a empresa A iniciou suas atividades em 1993. Especializou-se no desenvolvimento de softwares para conselhos regionais e federais de profissionais liberais, englobando: a) sistemas para a administração dos processos gerenciais dessas organizações; b) sistema de autoatendimento via internet para profissionais registrados, que disponibiliza alguns serviços oferecidos no atendimento presencial; c) software para gestão de eleições eletrônicas via internet. Em 2015, a empresa atende 75 clientes, espalhados nas cinco regiões do país, e conta com 24 colaboradores. $O$ faturamento médio da organização foi de 1,5 milhão de reais em 2014. Considerando a Classificação Nacional de Atividades Econômicas proposta pelo Instituto Brasileiro de Geografia e Estatística (IBGE), em 2007, a empresa, pelo quantitativo de funcionários, é catalogada como sendo de pequeno porte (de 10 a 49 funcionários).

\section{Empresa Beta}

Considerada a maior empresa embarcada no Porto Digital do Recife, a empresa B obteve faturamento próximo dos 60 milhões de reais em 2012 e um quadro de funcionários com quase 600 colaboradores, considerada, segundo a classificação do IBGE (2007), uma empresa de grande porte. Fundada em 1996, a organização desenvolve soluções que abrangem todo o processo de geração de inovação no setor de tecnologia da informação e comunicação. Entre as principais áreas de atuação 
da empresa estão gestão e execução de projetos, consultoria, educação e criação de negócios. Conta com quatro representações nas cidades de Recife (sede), Sorocaba (SP), São Paulo (SP) e Curitiba (PR).

\subsection{Coleta de dados}

Considerando o objetivo da pesquisa, optou-se por uma abordagem qualitativa. Entende-se que esse corte metodológico propicia, neste caso, melhor entendimento sobre os cenários apresentados e, consequentemente, pode-se relacionar os elementos inerentes aos processos de orientação ao mercado praticados por ambas as empresas estudadas. Portanto, conduziram-se aqui dois estudos estudo de caso, pois, conforme relata GIL (2008), esse método é indicado para: a) explorar situações da vida real cujos limites não estão claramente definidos; b) descrever a situação do contexto em que se está sendo feita determinada investigação; c) explicar as variáveis causais de determinado fenômeno em atividades muito complexas.

O objetivo deste estudo é apresentar dois cenários distintos em relação ao tema tratado. A empresa A, na qual um dos pesquisadores foi colaborador, apresenta indícios de que as suas práticas de orientação ao mercado estavam deficitárias, tendo em vista a perda de liderança no segmento no qual a empresa atua. Dada a hipótese, realizou-se entrevista com o gerente-geral da organização.

A empresa B, por sua vez, é reconhecida como um dos centros de inovação e pesquisa em soluções de TIC mais dinâmicos do Brasil. Com sede em Recife e embarcada no Porto Digital, parque tecnológico cuja "atuação se dá nos eixos de software e serviços de tecnologia da informação e comunicação e economia criativa, com ênfase nos segmentos de games, multimídia, cine-vídeo-animação, música, fotografia e design" (PORTO DIGITAL, 2015). A entrevista foi feita com um dos gerentes de negócios da organização.

Os dados para análise foram obtidos por meio de entrevistas estruturadas com base no formulário de avaliação proposto por Day, com a finalidade de "ilustrar os traços das organizações orientadas para o mercado e ajudar equipes a estabelecer prioridades para seu programa de mudança" (2001, p. 237). As perguntas foram estruturadas de acordo com cinco dimensões: 
I. Orientação geral: valores, crenças e comportamento.

II. Capacidade de sentir o mercado.

III. Capacidade de relacionamento com o mercado.

IV. Visão estratégica.

V. Sistemática organizacional.

O formulário de avaliação propõe uma escala diferencial de quatro pontos: as marcações no lado direito representam um desempenho superior ou a melhor prática de orientação para o mercado, os registros mais à esquerda, por sua vez, indicam práticas deficientes. Entretanto, esse índice não foi utilizado, pois optou-se pela elaboração de um protocolo com base em algumas perguntas sugeridas por Day (2001) para cada uma das dimensões apresentadas. Yin (2011) entende o protocolo como um instrumento capaz de aumentar a confiabilidade dos estudos de caso. Martins (2008) observa que o protocolo apresenta um conjunto pré-definido de procedimentos que auxiliam na condução da estratégia da pesquisa, permitindo que o estudo seja replicado. Da mesma forma, oferece condições para averiguar a confiabilidade do estudo, ou seja, "obterem-se resultados assemelhados em aplicações sucessivas a um mesmo caso" (2008, p. 10).

No que tange à análise dos resultados, foi realizada uma análise de conteúdo, método que, na visão de Bardin (2006), apresenta-se como um conjunto de técnicas de análise das comunicações que faz uso de procedimentos sistemáticos e objetivos de descrição do conteúdo das mensagens. Realizou-se a transcrição das entrevistas e a identificação dos pontos mais importantes do registro com base no modelo proposto por Day (2001) para orientação ao mercado, considerando as dimensões de estrutura, aptidões e cultura. Para tanto, foi montado um mapa de codificação, descrito no Quadro 4: 
Quadro 4 - Mapa de codificação para identificação dos elementos de orientação ao mercado propostos por George Day

\begin{tabular}{|c|c|c|}
\hline Elementos & Subelementos & Definição \\
\hline \multirow{3}{*}{ 1. Estrutura } & $\begin{array}{l}\text { 1.1 Valor superior para o } \\
\text { cliente }\end{array}$ & $\begin{array}{l}\text { Diferencial competitivo presente "do projeto } \\
\text { dos produtos à execução do pedido" (p. } 21) \text {. }\end{array}$ \\
\hline & 1.2 Coerência estrutural & $\begin{array}{l}\text { Equipes transfuncionais, cultura de qualidade } \\
\text { e aptidão para relacionamento com o mercado } \\
\text { (p. 24). }\end{array}$ \\
\hline & 1.3 Adaptabilidade & $\begin{array}{l}\text { Criação de uma estrutura que combine a pro- } \\
\text { fundidade de conhecimento encontrada em } \\
\text { uma hierarquia vertical com a sensibilidade } \\
\text { das equipes operacionais verticais (p. } 26 \text { ). }\end{array}$ \\
\hline $\begin{array}{l}\text { 2. Cultura orientada } \\
\text { para fora }\end{array}$ & - & $\begin{array}{l}\text { Crenças, valores e comportamentos dominan- } \\
\text { tes enfatizando valor superior para o cliente e } \\
\text { busca contínua de fontes de vantagem (p. 20). }\end{array}$ \\
\hline \multirow[t]{3}{*}{ 3. Aptidões } & 3.1 Sentir o mercado & $\begin{array}{l}\text { Abrir a mente coletiva a novas informações } \\
\text { para antever oportunidades e novas ameaças } \\
\text { da concorrência, além de prever com maior } \\
\text { precisão como o mercado irá reagir a mudan- } \\
\text { ças na estratégia (p. } 90 \text { ). }\end{array}$ \\
\hline & $\begin{array}{l}\text { 3.2 Relacionar-se com o } \\
\text { mercado }\end{array}$ & $\begin{array}{l}\text { Disposição para mudar suas mentalidades e } \\
\text { seus comportamentos, adquirir conhecimento } \\
\text { total a respeito de seus clientes mais valiosos } \\
\text { e integrar e alinhar seus processos mais im- } \\
\text { portantes (p. 142). }\end{array}$ \\
\hline & 3.3 Visão estratégica & $\begin{array}{l}\text { Utilização de um processo adaptável de pla- } \\
\text { nejamento e antecipação ao mercado (p. 204). }\end{array}$ \\
\hline $\begin{array}{l}\text { 4. Base comparti- } \\
\text { Ihada de conheci- } \\
\text { mentos }\end{array}$ & - & $\begin{array}{l}\text { A empresa coleta e dissemina seus critérios } \\
\text { sobre o mercado (p. 20). }\end{array}$ \\
\hline
\end{tabular}

Fonte: elaboração do autor com base em Day (2001).

As marcações foram feitas nas transcrições das entrevistas, identificando, nas respostas dos gestores, as referências a cada um dos subelementos descritos da tabela acima.

\subsection{Análise de dados}

A análise das entrevistas revelou práticas distintas coordenadas pelos dirigentes de ambas as organizações no que diz respeito aos elementos constitutivos do modelo proposto por Day (2001). Visando preservar a identidade das empresas, 
elas serão identificadas como empresa Alfa e Beta e seus dirigentes, por dirigente A e dirigente $\mathrm{B}$.

\subsubsection{Estrutura}

Conforme relato do dirigente A, que ocupa o cargo de gerente-geral na empresa Alfa, a organização carece de uma estruturação que confira condições de permear o desenvolvimento dos seus produtos e serviços de valor superior ao cliente. Foi percebida a dificuldade da organização com relação a duas questões principais que dizem respeito ao subelemento estrutura:

a) a empresa A não consegue adotar práticas de avaliação de retorno sob investimento considerando o esforço empregado na ações que envolvem atendimento a cliente e desenvolvimento de melhorias e/ou demais implementações nos softwares comercializados. Tal prática permite conferir maior valor agregado ao produto e, consequentemente, facilitar o valor percebido pelo cliente";

b) pôde-se inferir que a empresa A apresenta dificuldade para construir uma estrutura organizacional que permita maior interação entre os membros da organização. Um arranjo com esta característica facilita a tomada conjunta de decisões, além de vivência de uma cultura colaborativa.

A conclusão registrada na alínea a pôde ser observada nos registros da entrevista com o Dirigente A. A opinião da gestora quando perguntada sobre o estabelecimento de missão, visão e valores e aplicação de visão de curto ou longo prazo nas atividades da organização foi:

Quando eu disse que é classificado como longo prazo, é porque não existe uma associação entre o esforço que vai se fazer e o valor agregado a isso. Não existe uma análise de ROI. Então muitas vezes são priorizadas ações cujo retorno vem ser a longo prazo. [...] Então nós acabamos muitas vezes priorizando ações que só vão ter retorno a longo prazo em detrimento de ações que poderiam ter um retorno mais rápido até com um esforço menor.

Ao ser perguntada sobre como a empresa trabalha a questão do valor percebido pelo cliente, a dirigente reconhece que esse é um tópico ainda a ser aperfeiçoado:

Esse é um dos nossos pontos fracos. Hoje em dia não existe um trabalho feito em relação ao valor percebido. Tanto que é muito comum ouvirmos dos de alguns clientes que eles "pagam muito". E então a partir do momento que a gente ouve isso a gente já identifica que tem algum problema. Primeiro porque a gente conhece o sistema e sabe da qualidade, dos benefícios e das suas vantagens. E segundo, quando você está satisfeito com as necessidades atendidas, dificilmente você vai ser a sensação de que está "pagando muito". 
Galhanone (2013) sugere que a empresa deve criar um sistema adequado de entrega desse valor, alinhado com o que os clientes esperam. Para a autora, parte dessa tarefa depende da habilidade de seus profissionais de marketing em planejar propostas muito bem definidas e de influenciar os vários processos básicos da empresa. A empresa Alfa, entretanto, além de não dispor de uma área dedicada às questões de marketing, teve sua estrutura organizacional concebida de forma peculiar, como relata o Dirigente A:

O normal é você estabelecer o organograma e você vai captar talentos para preencher as vagas que estão nele. Aqui foi o contrário. Todo mundo já ocupava cargos quando o organograma foi desenhado. Depois que eu cheguei aqui, era uma das coisas que senti falta, o estabelecimento de papéis, de responsabilidades. E isso ficou mais claro para mim quando eu fiz um curso na área de gestão de pessoas e a cada aula que eu presenciava, eu sentia mais e mais a necessidade de se ter isso formalizado como forma de nortear as pessoas no dia-a-dia. Sobre o que se espera delas e futuramente poder avaliá-las.

A resposta nos leva a refletir sobre a conclusão indicada na alínea b. Do ponto de vista da adaptabilidade, considerando-se o que expõe Day em relação à capacidade de a organização criar uma estrutura funcional e integrada que permita a entrega de valor ao cliente, é possível perceber que a empresa Alfa carece de uma organização que confira a adaptabilidade necessária para integrar processos e estabelecer sinergia entre os colaboradores para criar uma atmosfera benigna à inovação.

Como resposta a essas adversidades, conta o Dirigente A, foi estabelecido um grupo de trabalho chamado Comitê de Mudança, reunindo colaboradores das áreas comercial, desenvolvimento de software, suporte ao cliente, gerência geral e direção. A ideia do grupo é promover a integração das áreas da empresa, melhorar o debate sobre as implementações que são feitas no sistema e colher impressões sobre as atividades rotineiras de cada departamento.

Percebe-se, portanto, que o cenário mais frequente da empresa A apresenta características típicas de empresas de TIC em relação à estrutura e cultura de inovação, como registram Adler e Moura (2010). Os autores afirmam que não é difícil organizações de tecnologias da informação carecerem de cultura de inovação. Quando lançam mão de métodos para alcançá-la, fazem-no por meio de um processo pouco estruturado, distante das reais necessidades dos usuários para a qual a solução se destina.

Na empresa Beta, a estrutura é, na opinião do Dirigente B, favorável a um ambiente que propicie a colaboração. A opinião do dirigente é explicitada ao explicar os responsáveis pelo levantamento das necessidades dos clientes: 
Existe uma área que nós chamamos de área de negócios que é responsável por marketing e vendas. Esse setor, mais do que qualquer outro, tem que estar muito antenado em entender as necessidades do cliente. Isso, entretanto, não é restrito a essa área de negócios. Qualquer profissional é encorajado a fazer isso, a trazer insights. Nós temos mais de 100 projetos rodando no ano... Então é impossível o gerente de negócios estar acompanhado tudo isso. Todas essas pessoas que interagem com os clientes são encorajadas a captar as necessidades, que muitas vezes não são explícitas.

No que tange ao organograma da empresa B, percebe-se uma estrutura mais flexível, em consonância com a necessidade de a empresa apresentar-se como provedora de soluções práticas. Nas palavras do Dirigente B, "O nosso organograma muda constantemente. $\mathrm{E}$ uma coisa que prevalece é que ele é muito achatado, não tem muitos níveis, é basicamente CEO e diretores". Uma das consequências dessa mudança é o fato de os profissionais estarem em contato com múltiplos projetos, conhecendo o escopo de diferentes frentes de trabalho. "O profissional não espera também passar muito tempo numa coisa só. Ele pode estar em um projeto hoje e daqui a quatro meses ele pode estar em outro, e aí começa a aprender outras coisas, seu conhecimento começa a se acumular e a gerar mais experiência”.

Percebe-se aqui a presença de um elemento importante constituinte de um modelo organizacional para inovação. Queiroz (2007) menciona que as empresas que inovam buscam justamente manter uma estrutura de poucos níveis hierárquicos, organizando o trabalho em tudo de equipes de projetos, facilitando, com isso, a comunicação, coordenação e cooperação dos seus membros.

A disposição organizacional dos integrantes da empresa Beta permite também maior integração entre as equipes. Quando perguntado sobre o relacionamento entre as equipes de pesquisa e desenvolvimento e marketing/negócios, o Dirigente B revela que o objetivo que une os colaboradores é a entrega de valor para o cliente:

Nós não temos uma equipe de pesquisa e desenvolvimento. E isso talvez seja o motivo que facilita as coisas para nós. Não temos estrutura dessa maneira. Não estamos aqui para fazer isso. A gente não faz pesquisa do nada. A gente quer entregar valor para o cliente. Não existe aquele pensamento de: "Ah, eu sou P\&D” ou “Ah, eu sou marketing/negócios."

Embora não seja o caso da empresa Beta, é comum que as organizações de base tecnológica criem barreiras entre os setores de P\&D e marketing, seja por supervalorização de uma dessas áreas ou pelas diferenças de metas, necessidades e motivação. Contudo, é preciso entender que a interação entre as equipes técnica e de marketing é primordial, sobretudo, nos primeiros estágios de desenvolvimento de produto, como apontam Mohr et al. (2011). Para os autores, a voz que o marketing traz para o processo de inovação deve vir acompanhada do conhecimento 
oriundo do setor de $\mathrm{P} \& \mathrm{D}$, com o intuito de desenvolver um produto realmente voltado para as necessidades dos clientes.

\subsubsection{Cultura orientada para fora}

Day (2001) observa que as empresas orientadas para o mercado têm a cultura como elemento unificador concebido para oferecer qualidade e vantagens aos próprios clientes, além de criar diferenciais competitivos em relação à concorrência. Ao discorrer sobre as diferenças crenças, valores e normas que diferenciam as organizações orientadas para o mercado daquelas centradas em si mesmas, o autor elenca alguns tópicos considerados por ele pertinentes à discussão. Tais pontos puderam ser observados em ambas as entrevistas, conforme os relatos reproduzidos a seguir.

a) "A pesquisa de mercado é uma garantia para as decisões."

$\mathrm{Na}$ empresa Alfa, segundo o Dirigente A, não existe uma rotina de pesquisa de mercado formalizada. Entretanto, "existem aquelas demandas que surgem por parte do cliente que os setores comercial e de suporte reportam ao setor de desenvolvimento de software. Só que isso eu não considero uma prática de pesquisa de mercado, pois é muito limitado". A criação do Comitê de Mudança é uma das alternativas para contornar o problema.

Na empresa Beta, o Dirigente B afirmou que sua organização tinha, até pouco tempo, um profissional dedicado a questões de inteligência de mercado, responsável pela captura de informações, números e métricas sobre os mercados principais nos quais a empresa atua, bem como os dos clientes. A empresa chegou a contratar algumas ferramentas de conteúdo que traziam relatórios e notícias, agregando todas essas informações sobre o mercado e sobre determinado cliente. O dirigente B relata que a situação sem um profissional é um pouco diferente: “[...] Em vez de ter uma pessoa dedicada como antes, nós temos uma área de marketing que não é focada em inteligência de mercado. É uma área que nos apoia em tudo, inclusive com pesquisa de mercado".

b) "O comportamento dos concorrentes pode ser previsto e influenciado."

Não há, na empresa Alfa, metodologias de estudo de concorrentes. Conforme descreve o Dirigente A, "Não existe esse trabalho. A gente acaba sabendo de algumas dessas informações nos processos de licitação nos quais participamos ou em algumas visitas realizadas. Nessas ocasiões a gente acaba tendo como 
consequência essas informações. Mas o objetivo principal não é esse”. Quando perguntada se colaboradores das equipes de desenvolvimento de software e suporte ao cliente conseguem identificar os principais concorrentes da empresa, a resposta dada foi afirmativa.

A empresa Beta também não adota processos formais de estudo dos concorrentes. Entretanto, é feita uma coleta de informações a partir de "[...] notícias, conversando e analisando o movimento dos concorrentes", como afirma o dirigente B. O gestor ainda observa que:

[..] mais importante do que os concorrentes diretos são os outros concorrentes. Por exemplo, se uma empresa deixar de fazer um projeto conosco para fazer treinamento interno, isso é encarado como uma concorrência. Tudo o que ameaça um cliente não buscar a nossa empresa para desenvolver alguma coisa, a gente encara como concorrente. Não é só aquele que vai mandar uma proposta. É uma ameaça também se a gente, por exemplo, fica muito caro ou se a gente oferece a proposição de valor é errada. O governo está sempre modificando leis e isso também nos afeita... Empresas que não são de tecnologia, empresas de design, por exemplo, também são nossos concorrentes. Então, resumindo, olhamos as duas coisas: o concorrente direto e também tudo que pode estar nos ameaçando, tirando negócio de nós.

c) "O conhecimento do cliente é um ativo valioso."

Verifica-se que na empresa Alfa as práticas de estudo de clientes ainda são incipientes. Segundo o Dirigente A, é utilizada uma ferramenta de pesquisa de satisfação que avalia o atendimento do analista de suporte, além de haver uma categoria SRE (sugestão, reclamação e elogio), que permite ao cliente fazer outras observações. Mas, como observa o gerente, "Basicamente é isso... Hoje a gente se limita a verificar as respostas dessas pesquisas, que têm um retorno muito baixo, considerando o valor de atendimento que é feito". Outra prática destacada é a reunião do Comitê de Mudanças, em uma tentativa de universalizar as informações colhidas sobre os clientes no dia a dia da instituição. Também são realizadas visitas esporádicas aos clientes. Conforme relata o Dirigente A:

Sempre foi intenção de a gente ter um representante ou mais de um representante que estivesse constantemente visitando o cliente para poder desenvolver e manter esses relacionamentos. Mas dada a questão territorial, já que a gente tem clientes em todo o Brasil, continua sendo inviável. Mas a gente percebe que essa é uma das formas mais efetivas porque nas poucas vezes que a gente tem a oportunidade de visitar, é bem proveitoso.

A tentativa de estabelecimento de um novo cenário para estimular a participação efetiva dos colaboradores quanto a esse aspecto encontra fundamento no que dizem Maia et al. (2014) sobre o tema. Para os autores, "a capacidade continuada dos colaboradores de uma empresa para inovar no dia a dia, como rotina da empresa, de forma participativa e sem medos ou receios, é fundamental”. Na empresa B, 
identifica-se ainda a tendência a estimular o perfil empreendedor dos seus colaboradores. Comenta o Dirigente $\mathrm{B}$ que:

Uma coisa que é importante é esse espírito empreendedor. Se forem pessoas que têm o perfil de receber a tarefa e executar da melhor maneira possível, não funciona. Não todas, mas tem que ter umas pessoas que têm o perfil de empreendedor: "Eu vou fazer uma coisa diferente. Eu vou contra a maré. Eu estou disposto a fazer isso dentro da empresa”... Então isso acontece aqui.

Alguns eventos promovidos pela organização também têm o intuito de projetá-la para o mercado como centro de referência em inovação. Entre as práticas, o Dirigente B cita:

A gente faz maratona de inovação. Então tem dia em que vários profissionais passam o dia falando sobre vários tópicos de inovação. Isso é transmitido via web e é uma forma de se aproximar do mercado, de mostrar para o mercado que nós fazemos inovação. Nós promovemos também o dia da tecnologia, trazendo especialistas de uma determinada área... É um evento mais técnico que discute sobre uma determinada tecnologia ou mercado... Nós fizemos diversas iniciativas com cidades inteligentes, com a internet das coisas, já fizemos coisas com saúde. Então estamos sempre fazendo eventos, ações, às vezes, com os clientes, às vezes, com outras pessoas, para se aproximar do mercado, para o mercado nos perceber como um centro de inovação. E a gente começa a se relacionar melhor com o mercado. Promover palestras para começar debates na sociedade.

A afirmação do dirigente B corrobora Day, que afirma que "o grau em que o comportamento orientado para o mercado está embutido na cultura - valores, normas e crenças comuns que dão significado aos membros da organização - é cada vez mais levado em conta".

\subsubsection{Aptidões}

As organizações orientadas para o mercado desenvolvem uma série de habilidades específicas que as tornam capazes de se posicionarem estrategicamente a respeito das tendências do mercado. Essa vantagem pode significar atração de clientes, melhora da relação com distribuidores e contenção dos concorrentes (DAY, 2001).

Na empresa Alfa, segundo o dirigente entrevistado, não há processos formalizados de pesquisa de mercado. Conta ele que "[...] Foi-se pensada a criação de um papel para isso que é o de analista de negócios, mas houve evolução quanto a isso. Esse papel foi abortado e a pessoa que iria exercê-lo voltou para o setor de suporte técnico", afirma. Entretanto, o dirigente também fala que "[...] existem aquelas demandas que surgem por parte do cliente que os setores comercial e de suporte reportam ao setor de desenvolvimento de software. Só que isso eu não considero uma prática de pesquisa de mercado, pois é muito limitado". 
Quanto ao estudo dos concorrentes, o gerente confirma não existir rotinas dedicadas a essa atividade. As principais informações sobre o trabalho deles são coletadas nos processos de licitação dos quais a empresa Alfa participa, além das visitas aos clientes que são realizadas.

No que diz respeito às práticas de relacionamento com os clientes, o Dirigente A julga que a empresa em que trabalha estabelece relações de longo prazo com eles, mas avalia que quando classifica a interação desta maneira, "[...] é porque não existe uma associação entre o esforço que vai se fazer e o valor agregado a isso. Não existe uma análise de ROI. Então muitas vezes são priorizadas ações cujo retorno vem ser a longo prazo". Entre outras práticas que estimulam o bom relacionamento com 0 cliente promovidas pela empresa, estão o envio de brindes durante o período natalino, a realização de pronto atendimento de demandas solicitadas pelos clientes - "sem sequer avaliar o retorno financeiro sobre isso" -, como comenta o Dirigente A e outras ações "mais sutis" como a prática mais branda de cobrança pelos serviços prestados e a extrapolação do limite de horas vigente nos contratos para suporte ao usuário.

Quanto à questão do planejamento estratégico da organização, o dirigente $\mathrm{A}$ informou que a empresa Alfa não dispõe desde processo gerencial:

Eu digo que a gente ainda está muito incipiente na questão de planejar. Não existe essa prática aqui. Existem tentativas isoladas. O setor de desenvolvimento de software tem uma tradição mais dinâmica [...] com metodologia ágil. O setor de suporte, por sua vez, há tentativas de se implementar algumas práticas com base na biblioteca ITIL que também defendem a questão do planejamento. Mais uma vez eu volto a dizer são tentativas ainda muito verdes que requerem ainda maturação, principalmente, para os demais setores como o próprio suporte, o comercial, que ainda está muito carente, e me parece que o único setor em que há planejamento por conta da adoção da metodologia que foi o SCRUM, seja o setor de desenvolvimento de software.

É perceptível a tentativa da empresa Alfa de estabelecer métodos que garantam às áreas o acompanhamento de suas atividades. Entretanto, fica clara a falta de unidade e congruência interssetorial no que diz respeito à obediência de um plano estratégico que seja capaz de conferir à organização a capacidade de alocar recursos humanos e materiais para execução de atividades orientadas ao cumprimento de metas. É dessa maneira que, segundo Lima e Carvalho (2011), a empresa torna-se apta a adequar os objetivos e recursos da empresa às mudanças de oportunidades de mercados, aproveitando-as de maneira mais estratégica com seus recursos (dinheiro, capital humano, intelectual, produtos diferenciados, outras vantagens perante os concorrentes), estabelecendo objetivos (o que se deseja atingir) e estratégias (como chegar aos objetivos) factíveis.

A empresa B, por sua vez, apresenta elementos que evidenciam uma maturidade mais elevada, tendo em vista que a organização, nas palavras do Dirigente B, 
permite a criação de um planejamento participativo, reforçando o caráter empreendedor que a entidade deseja desenvolver em cada colaborador.

É completamente cooperativa, ou seja muito democrática. Às vezes, isso traz problemas, mas eu acho isso acaba sendo o ponto forte da instituição. Qualquer área, qualquer pessoa pode tocar uma coisa, basta convencer os demais que aquilo é importante e interessante. É óbvio que a alta direção dá alguns direcionamentos. Mas não se restringe a eles.

Na opinião do Dirigente B, esse processo é importante porque "engaja as pessoas, faz com elas representem". Além disso, a empresa B também desenvolve outras atividades para potencializar a cooperação entre seus colaboradores e a difusão de conhecimento sobre assuntos estratégicos para a atuação de mercado da organização bem como o aperfeiçoamento das habilidades dos colaboradores. Além da maratona de inovação já citada pelo Dirigente B, acrescenta-se:

[...] Outro exemplo, dois anos já que a gente faz, que um ciclo de palestras no estilo do TED, só que interno. Passamos uma semana com oito, dez palestras. A gente convida CEOs, diretores, gente de opinião com quem temos um relacionamento, eles não são pagos, eles querem vir, e falam sobre sistemas teve gente aqui falando sobre urbanização, sobre câncer, sobre experiências internacionais, varejos, sobre o que é estudar o futuro. Isso tem sido feito interno, mas queremos tornar isso uma das principais ferramentas para o público externo. Promover palestras para começar debates na sociedade.

As tentativas de relacionamento com o cliente e o mercado surgem, portanto, como vitais para a sobrevivência e o destaque das organizações em relação à concorrência e ao próprio mercado.

\subsubsection{Base compartilhada de informações}

Las Casas e Garcia (2007) reconhecem a comunicação como um dos diferenciais competitivos de maior valor para empresas. Para os autores, nem sempre os produtos, os preços ou o potencial de distribuição são capazes de diferenciar uma marca de outra, muitas vezes, é o valor agregado por meio da comunicação e pela proximidade com os consumidores. A base para a construção desse diferencial reside na capacidade das organizações de estimularem a troca de informações entre os participantes das equipes para que o conhecimento possa construir relacionamentos com clientes, disseminar a estratégia da empresa e aumentar o comprometimento dos funcionários com as necessidades do mercado.

Em ambas as empresas, registrou-se certa dificuldade de compartilhamento das informações estratégicas entre os setores. No caso da empresa A, antes da instalação do Comitê de Mudança, não havia um processo instaurado de compartilhamento de informações. A organização faz uso de ferramentas de gestão do relacionamento com 
os clientes, mas os registros não circulam entre as áreas. Segundo o Dirigente A, “[...] não existe nenhuma estratégia por trás da ferramenta. E é aquilo: não ainda ter ferramentas e pessoas, apenas. Você precisa de um processo pra fechar esse triângulo". $\mathrm{O}$ gerente reconhece essa dificuldade, pois mesmo em uma organização de pequeno porte existem barreiras impeditivas à comunicação entre os setores:

Circulam, até por conta dos grupos informais, na hora do cafezinho... Mas de uma maneira muito informal. Intersetorialmente não existe muita interação. São feitas reuniões de final de ano... Mas não existem momentos dedicados para a comunicação. Dentro dos próprios setores existe. $\mathrm{O}$ setor de suporte, por exemplo, realiza reuniões semanalmente. O setor de desenvolvimento também, por conta da própria metodologia que eles adotam.

Situação diferente é percebida na empresa B. Ao ser perguntado sobre os processos de pesquisa de mercado e disseminação de informações, o Dirigente B foi categórico:

Aqui a gestão da informação é muito importante. Toda quarta-feira à tarde, temos um horário reservado para encontros. Ele é chamado de intervalo técnico. Mas ele não é só técnico. É um espaço em que qualquer pessoa pode ir lá e assistir presencialmente ou de suas baias, caso não possa se deslocar por estar dedicado a um projeto no momento. Nesses estudos, ocorrem apresentações de projetos, de experiências, pesquisas que fazemos e coisas que deram errado, além de muita informação sobre determinado mercado ou cliente.

A prática condiz como que o que afirma Yanaze sobre a importância da informação, reconhecendo-a como "um dos inputs mais importantes para uma organização que pretende sobreviver e crescer no mercado; é a matéria-prima de suas decisões" (2011, p. 270).

A difusão de conhecimento sobre clientes, mercados, processos de desenvolvimento de sistemas e tecnologias, além de debates constantes sobre temas atuais, podem ajudar as empresas de base tecnológica a superar os desafios impostos pelo mercado de TICs. Mohr et al. (2011) aconselham, ainda, que a difusão do conhecimento sobre clientes e mercado, especialmente para as equipes técnicas, seja intensificada por meio do contato direto desses grupos tanto com clientes como com outras fontes de informação.

\section{Considerações finais}

O presente trabalho buscou estabelecer um comparativo entre duas realidades distintas de empresas de base tecnológica e seus processos de orientação ao mercado considerando o modelo proposto por George Day em 2001. Considerando os elementos que o compõem, as organizações foram avaliadas e apresentaram 
alguns elementos importantes para que se práticas exitosas e deficitárias sejam identificadas e debatidas.

Verificou-se que uma estrutura organizacional enrijecida não estimula a participação dos colaboradores na opinião quanto a inovações nos produtos e serviços oferecidos. A falta de planejamento estratégico, de maior sensibilidade nas questões de marketing e na disseminação de conhecimento em diversos setores, a exemplo de uma das empresas aqui analisada, acabaram por criar um ambiente no qual prevalece a retração. O relacionamento com os clientes torna-se comprometido em virtude de não haver metas, indicadores e outros índices capazes de oferecer norte aos colaboradores. É o que Moh et al. (2011) classificam como "rotinas enraizadas", que acabam por se tornar barreiras a uma avaliação realista e mais atenta às novas oportunidades de mercado. Em cenários como esse, é tolhida a habilidade de uma empresa de ser inovadora e de agir sobre informações do mercado.

O grau de maturidade desejado pode ser alcançado, conforme verificado neste estudo, com processos bem desenhados, criando condições de "oferecer valor ao cliente". As práticas de integração que ocorrem internamente, a exemplo de intervalos técnicos e de palestras sobre temas pertinentes ao mercado, podem permitir que os stakeholders percebam a empresa como centro de referência nas atividades por ela desenvolvidas.

Analisando o modelo de orientação ao mercado proposto por Day (2001), verificou-se que esse pode ser um caminho para apresentar processos e estruturas capazes de conferir às organizações a sensibilidade necessária para criarem um ambiente virtuoso que permitam atenção e capacidade técnica para atender as exigências de clientes e mercados. Contudo, ao considerar o mercado de tecnologia da informação e comunicação, é necessário considerar alguns tópicos que não são apresentados com o detalhamento necessário no modelo de Day (2001). Entre eles, vale destacar o processo de planejamento estratégico que considere as incertezas do mercado e das tecnologias, a volatilidade da concorrência, os processos de decisão de compra por parte do cliente e questões de marketing como propaganda e promoção e gestão de marca em mercados de alta tecnologia.

O estudo em questão não assume caráter conclusivo, em virtude das limitações da pesquisa. Sugere-se em iniciativas futuras que os pesquisadores investiguem também as interpretações dos colaboradores das empresas, com o objetivo de se estabelecer um retrato mais diverso das realidades estudadas.

É importante considerar que as conclusões aqui registradas não são aplicadas, necessariamente, em organizações de porte semelhante às empresas aqui analisadas. Seus resultados, explícitos aqui na forma de estudo de caso, retratam tão-somente um corte de realidade momentâneo das duas organizações. 


\title{
Market orientation in technology based companies software producers: an analysis of George Day model
}

\begin{abstract}
This article analyzes the elements and processes that make up the market orientation in Information and Communication Technology segment in technology-based companies in the city of Recife, Pernambuco. To that end, are described both the concept of technologybased company and the process of market orientation, with special attention to the model proposed by George Day and detail of the components of his approach. It was conducted a case study whose population is composed of two Pernambuco companies that develop software as its main activity. The population is composed by two Pernambuco companies which develop software as their main activity. The instrument used was an interview which is based on a questionnaire prepared by Day capable of establishing typical characteristics of market-oriented organizations and providing the necessary inputs to the implementation of improvements by managers and collaborators.
\end{abstract}

Keywords: Marketing. Market orientation. Information technology.

\section{Orientación para el mercado de empresas de base tecnológica productoras de software: un análisis según el modelo de George Day}

\section{Resumen}

Este artículo analiza los elementos y procesos que conforman la orientación al mercado en el segmento de Tecnología de Información y Comunicación en las empresas de base tecnológica en la ciudad de Recife, Pernambuco. A tal fin, se describen el concepto de empresa de base tecnológica, el proceso de la OPM, con especial atención al modelo propuesto por George Day. A continuación se realizó un estudio de casos cuya población está compuesta de dos empresas que desarrollan software como actividad principal. El instrumento utilizado fue una entrevista elaborada sobre la base de un cuestionario elaborado por Day capaz de establecer características típicas de las organizaciones orientadas al mercado y proporcionar los insumos necesarios para la implementación de mejoras por parte de gerentes y colaboradores.

Palabras clave: Marketing. Orientación al mercado. Tecnología de la información. 


\section{Nota}

1 Disponível em: <http://www.finep.gov.br/biblioteca/glossario>. Acesso em: 27 dez. 2016.

\section{Referências}

ABBADE, Eduardo Botti; ZANINI, Roselaine Ruviaro; SOUZA, Adriano Mendonça. Orientação para aprendizagem, orientação para mercado e desempenho organizacional: evidências empíricas. Revista de Administração Contemporânea, Curitiba, v. 16, n. 1, p. 118-136, fev. 2012.

ADLER, Isabel Krumholz; MOURA, Heloisa Tavares de. A criação de uma cultura de inovação em empresas de tecnologia da informação apoiada pelos métodos do Design Estratégico. In: CONGRESSO BRASILEIRO DE PESQUISA E DESENVOLVIMENTO EM DESIGN, 9, 2010, São Paulo: Universidade Anhembi Morumbi, 2010. p. 1-13. Disponível em: <http://blogs.anhembi.br/congressodesign/anais/artigos/69523.pdf>. Acesso em: 20 abr. 2015.

ASSOCIAÇÃO BRASILEIRA DAS EMPRESAS DE SOFTWARE. Mercado brasileiro de software: panorama e tendências, 2014. São Paulo, 2014. 24 p.

ASSOCIAÇÃO DAS EMPRESAS DE SERVIÇOS DE PROCESSAMENTO DE DADOS. Assespro. Censo do setor de TI 2014: principais resultados para o Brasil em comparação com os demais países. 2014. Disponível em: <http://assespro.org.br/biblioteca/dados-mercado/2014-censo-aleti-do-setor-de-ti-2014-resultados/>. Acesso em: 20 abr. 2015.

BARDIN, L. Análise de conteúdo. Tradução de L. de A. Rego e A. Pinheiro. Lisboa: Edições 70, 2006.

BRASIL. INSTITUTO BRASILEIRO DE GEOGRAFIA E ESTATÍSTICA. Classificação Nacional de Atividades Econômicas. 2.0 Rio de Janeiro: IBGE, 2007. 616 p.

CAPON, Noel; GLAZER, Rashi. Marketing and technology: a strategic coalignment. American Marketing Association, Alabama, v. 51, n. 3, p. 1-14, jul. 1987.

CURI, Denise Pereira. Orientação para o mercado: a relação entre a Orientação para a tecnologia e o marketing relacional. 2007. 228 f. Tese (Doutorado em Engenharia) - Escola Politécnica, Universidade de São Paulo, São Paulo, 2007.

DAY, George S. A empresa orientada para o mercado: compreender, atrair e manter clientes valiosos. Porto Alegre: Bookman, 2001.

GALHANONE, Renata Fernandes. Valor percebido pelo consumidor de produtos de luxo: proposição de um modelo teórico. 2013. Tese (Doutorado em Administração) - Faculdade de Economia, Administração e Contabilidade, Universidade de São Paulo, São Paulo, 2013. Disponível em: <http:// www.teses.usp.br/teses/disponiveis/12/12139/tde-03062013-152622/>. Acesso em: 5 set. 2015.

GIL, Antonio Carlos. Métodos e técnicas de pesquisa social. 6. ed. São Paulo: Atlas, 2008.

KOHLI, Ajay K.; JAWORSKI, Bernard J. Market orientation: the construct, research propositions, and managerial implications. Journal of Marketing, Chicago, v. 4, n. 52. p. 1-14, abr. 1990.

LAS CASAS, Alexandre Luzzi; GARCIA, Maria Tereza. Informação em marketing: utilização da tecnologia da informação como diferencial em estratégias de marketing. São Paulo: Novatec, 2007.

Teoria e Evidência Econômica - Ano 22, n. 47, p. 385-412, jul./dez. 2016 
LIMA, Gustavo Barbieri; CARVALHO, Dirceu Tornavoi de. Plano estratégico de marketing: proposta de uma análise teórica. Remark, São Paulo, v. 10, n. 2, p. 163-187, 6 dez. 2011.

MAIA, Celso et al. Fatores da cultura organizacional que condicionam ou limitam o processo de inovação. Revista Capital Científico, Eletrônica, Guarapuava, v. 3, n. 12, p. 1-18, jul./set. 2014. Disponível em: <http://revistas.unicentro.br/index.php/capitalcientifico/article/download/2646/2321>. Acesso em: 20 maio 2015.

MARCOVITCH, Jacques; SANTOS, Silvio A. dos; DUTRA, Ivan. Criação de empresas com tecnologias avançadas: as experiências do PACTo/IA-FEA- USP. Revista de Administração da Universidade de São Paulo, São Paulo, v. 21, n. 2, p. 3-9, 1986.

MARTINS, Gilberto Andrade. Estudo de Caso: uma reflexão sobre a aplicabilidade em pesquisas no Brasil. Revista de Contabilidade e Organizações, Ribeirão Preto, v. 2, n. 2, p. 9-18, 2008.

MOHR, Jakki et al. Marketing para mercados de alta tecnologia e de inovações. São Paulo: Pearson, 2011. 376 p.

MONÇORES, Paulo de Jesus. Marketing de relacionamento individualizado em empresas prestadoras de serviço de tecnologia de informação, no contexto business-to-business: uma vantagem competitiva? 2004. Disponível em: <http://www.unifae.br/publicacoes/pdf/art_cie/art_22.pdf>. Acesso em: $1^{\circ}$ maio 2015.

NARVER, John C.; SLATER, Santley F. The effect of a market orientation on business profitability. Journal of Marketing, Chicago, v. 54, n. 4, p. 20-35, out. 1990.

OLIVEIRA, Thiago dos Santos. A relação entre orientação para o mercado e conhecimento de mercado. Revista Pretexto, Belo Horizonte, v. 7, n. 1, p. 25-34, jan./jun. 2006.

PEREIRA, Beatriz de Castro Sebastião. Implementação e mensuração da estratégia de orientação para o mercado. In: SEMINÁRIOS EM ADMINISTRAÇÃO, 8, 2005, São Paulo. Artigos... São Paulo: Faculdade de Economia, Administração e Contabilidade da Universidade de São Paulo, 2005. p. 1-13.

PORTO DIGITAL. O que é o Porto Digital. Portal institucional. 2015. Disponível em: <http:// www.portodigital.org/parque/o-que-e-o-porto-digital>. Acesso em: 4 maio 2015.

PISCOPO, Marco Roberto. Empreendedorismo corporativo e competitividade em empresas de base tecnológica. Revista de Administração e Inovação, São Paulo, v. 7, n. 1, p. 131-150, jan./mar. 2010.

QUEIROZ, Ana Carolina S. (Org.). Modelos organizacionais para inovação. In: MOREIRA, Daniel Augusto; QUEIROZ, Ana Carolina S. Inovação organizacional e tecnológica. São Paulo: Thomson, 2007. p. 79-100. cap. 4.

RACHEL, Lucimar Azevedo; SALOMÃO, Aretha Henrique Martins. Cultura e clima organizacional como estratégias de impacto no desempenho. Revista Eletrônica Machado Sobrinho, Juiz de Fora, v. 4, n. 0, p. 1-14, jul./dez. 2011.

SBRAGIA, Roberto; LIMA, Manuella Oliveira. Orientação para mercado e interface funcional: evidências em projetos de desenvolvimento de novos produtos. Revista de Administração e Inovação, São Paulo, v. 10, n. 3, p. 184-207, jul./set. 2013.

YANAZE, Mitsuru Higuchi. Gestão de marketing e comunicação: avanços e aplicações. 2. ed. São Paulo: Saraiva, 2011.

YIN, Robert. K. Estudo de caso: planejamento e métodos. 2. ed. Porto Alegre: Bookman, 2001. 164 p. 